\title{
Gender-Biased English Language in Hip Hop Music
}

\author{
Aya Mohammed Sallam ${ }^{1}$, Ji Young Shim ${ }^{2 *}$ \\ IMA TESOL Program, English Department American University of Sharjah \\ 2Assistant Professor Department of English American University of Sharjah PO Box 26666, Sharjah United \\ Arab Emirates
}

*Corresponding Author: Ji Young Shim, Assistant Professor Department of English American University of Sharjah PO Box 26666, Sharjah United Arab Emirates

\begin{abstract}
This study investigated gender and sexuality discourse in hip-hop by using the FPDA (Feminist Post-Structuralist Discourse Analysis) approach. The samples were drawn from the chart of Billboard Hot 100 in February, 2020 and the lyrics of 20 contemporary hip hop music were analyzed according to two variables: (a) the theme of gender-biased language and (b) the gender of the artist. Results of the study indicate that gender-biased language exists in hip-hop music and both male and female artists predominantly used much more gender-biased language against women rather than men, showing no correlation between gender-biased language against a specific gender and the gender of the language user.
\end{abstract}

KEYWORDS: English as a global language, gender-biased language, hip-hop, objectification

ABbREviations: FPDA Feminist Post-Structuralist Discourse Analysis, WHO World Health Organization

\section{INTRODUCTION}

Music is a great way to learn a foreign language. Instead of memorizing various rules of a language, language learners can be introduced to authentic expressions in a foreign language while enjoying world popular music. According to the Billboard Hot 100 chart for the week of February 2nd, 2020, $49 \%$ of music played on radio stations and streamed online is hip-hop/R\&B. This prominence emphasizes how hip-hop/R\&B is the most popular music in the modern world, and the lyrics of this genre may have a great influence on English language learners around the world. However, it has been argued that the hip-hop industry is interested in profiting from gender-biased language by utilizing sexist remarks against women. For instance, De Leon (2007) states that "The Hip-Hop industry isn't really interested in the diversity or even really the art. It's more interested in products and profit obtained by toxic masculinity and sexist remarks towards women" [1].This further suggests that listeners to this popular gender of music are unknowingly exposed to gender-biased language. Furthermore, music has a much deeper cognitive effect on how individuals behave. According to Murphey (1990), "Songs may act as an activator cognitively, or be a strategy in the ontogenetic development of language and behavior" [2]. Because of the dominance of Hip-Hop in world music and popular culture, coupled with the status of English as a global language, there is a growing concern that English language learners may learn the profanity of the language towards either gender without realizing its far psychological effects.

Then a questions arises: what is gender-biased language? The Oxford Dictionary defines a gender bias as the inclination towards or prejudice against one gender. Hence, gendered language or genderbiased language is described as a language that has a bias towards a particular sex or social gender [3].While hip-hop music is blamed for its gender-biased language [4,5], there is very little research done in this field and the extant studies report gendered-language biased against women only $[6,7]$. Thus, the present study investigates whether (a) the lyrics of hip-hop music are biased against any specific gender (e.g., male vs. female) and also (b) whether gender-biased expressions are related to the gender of the singer/artist.

\subsection{The Present Study}

\subsubsection{Theoretical Framework}

Judith Baxter developed the Feminist Post-Structuralist Discourse Analysis (FPDA) approach, with the focus on power dynamics between men and women. FPDA examines the way in which speakers 
negotiate their identities, relationships and positions in the world [8]. The FPDA approach has also been used by a number of scholars in the field of gender and language. For instance, Sauntson (2011) employs the FPDA approach in her study on spoken classroom discourse to "account more fully for the fluidity and multiplicity of gendered discourses emerging from the data" [9, p.42]. Because FPDA considers both genders, male and female, and their power relation as an integral part of its analysis and acknowledges the existence of power fluctuation between men and women, this paper adopted the FPDA approach as a theoretical framework to examine gender-biased language in relation to the role of gender itself. This means that unlike many other gender and language studies that adopts the view that men are pictured as oppressors and women are portrayed as victims, the present study takes the neutral stance that gender-biased discourse can and may exist against both genders.

\section{Materials And Methods}

\subsection{Data Collection}

To investigate whether there exist any gender-biased expressions in word popular music, 20 hip-hop songs were selected from the Billboard's Hot 100 from the week of February 2, 2020. 10 out of these 20 songs were sung by male artists and the other 10 songs were sung by female artists. According to Neff, Billboard Hot 100 are voted based on club play, radio airplay, audience impressions, sales data, and streaming activity data as appropriate for each genre [7]. Lyric Find is a lyric licensing company that provides the official lyrics of all the 20 songs being analyzed from the Billboard Hot 100 on its website. Currently, it also licenses lyrics from over 5,000 music publishers around the world including Warner Music Group, Universal music Publishing Group, and Sony Music Publishing. Table 1 below shows the 20 songs selected for analysis in this study. The language of all the chosen songs was English.

Table1. The 20 hip-hop songs selected from the Billboard's Hot 100 from the week of February 2, 2020

\begin{tabular}{|c|c|}
\hline Songs by male artists & Songs by female artists \\
\hline The Box by Roddy Ricch & BITCH by Megan Thee Stalion \\
\hline Life is good by Future and Drake & Juicy by Doja Cat \\
\hline Roxanne by Arizona & South of the border by Cardi B \\
\hline Godzilla by Eiminem & Tusa by Nicki Minaj \\
\hline Bop by Da Baby & $P^{* *}$ fairy by Aiko \\
\hline Ballin by Mustard & HER by Slide \\
\hline Hot girl bummer by black bear & Say So by Doja Cat \\
\hline Heartless by the weekend & Easy by Danileigh \\
\hline Highest in the room by Travis scott & Come Thru by Summer Walker \\
\hline High fashion by Roddy Ricch & Good as Hell by Lizzo \\
\hline
\end{tabular}

\section{DATA ANALYSIS}

The lyrics of the above-mentioned 20 hip-hop music were analyzed to see if (a) gender-biased language is found towards to both male and female and also (b) if gender-biased expressions are related to any specific gender, male or female singers. To identify gender-biased language in these songs, the lyrics of selected songs were analyzed according to the five themes of gender-biased language that were initially categorized in Neff [7]. The five themes suggested in Neff are: (1) Portrayal of women as stereotypes, (2) Portrayal of women in traditional gender roles, (3) Portrayal of women as inferior to men, (4) Portrayal of women as objects, and (5) portrayal of violence against women.

While these five themes provide a way to distinguish different types of gender-biased language, Neff fails to provide the precise definition of these themes and examples to represent each theme. In addition, Neff's study includes gender-biased language against women only, not against men. Thus, each theme of gender-biased language has been refined with an inclusion of both male and female genders.

\subsection{Five Different Themes of Gender-Biased Language}

\section{Theme I: Portrayal of Women and Men as Stereotypes}

The portrayal of women and men as stereotypes may differ according to the commonly assumed gender roles. According to the United Nations Human's rights, "A gender stereotype is a generalized 
view or preconception about attributes or characteristics, or the roles that are or ought to be possessed by, or performed by women and men" [10]. What makes gender stereotyping harmful is its ability to limit both women's and men's capacity to "develop their personal abilities, pursue their professional careers and make choices about their lives". Blackstone (2003) provides a clear distinction between gender stereotypes and gender roles: "Gender roles are sometimes created on the basis of stereotypes about gender. Gender stereotypes are oversimplified understandings of males and females and the differences between them. Individuals sometimes base their perceptions about appropriate gender roles upon gender stereotypes." [11]. She furtherly provides a common example of a stereotype for each gender such as males are not emotional, and females are irrational and overly emotional.

\section{Theme II: Portrayal of Women and Men in Traditional Gender Roles}

The World Health Organization (2020) identifies traditional gender roles for men and women as "the roles, behaviors, activities, attributes and opportunities that any society considers appropriate for girls and boys, and women and men" [12]. Blackstone claims that an example of female gender roles in western society is to pursue the belief that "the feminine gender role prescribes that women should behave in ways that are nurturing" [11, p.357). On the other hand, an example of traditional male gender roles is "the heads of their households by providing financially for the family and making important family decisions" (p.357).

\section{$>$ Theme III: Portrayal Women/Femininity as Inferior to Men/Masculinity or Portrayal of Men/Masculinity as Inferior to Women/Femininity}

According to Gender Innovations, femininities and masculinities are "gender identities, th[at] are shaped by socio-cultural processes, not biology...Femininities and masculinities are plural and dynamic; they change with culture and with individuals" [13]. Thus, femininities and masculinities do not describe sexual orientation but rather represent "certain behaviors and practices widely recognized by a certain culture as feminine or masculine.". Neff highlighted common examples of phrases referring women or femininity being portrayed as inferior to men or masculinity [7]. Some of these phrases refer to women as "weak", "child-like" or refer to common feminine attributes negatively such as "belittling romance" (p.9).

\section{Theme IV: Objectification of both Women and Men}

Stanford Encyclopedia of Philosophy defines objectification as "the seeing and/or treating a person, usually a woman, as an object" and provides a list of some possible ways to objectify an individual [14]. In order to identify objectification with reference to our study, any instance from the categories found in the lyrics of identified songs was considered as an attribute of objectification of either gender.

\section{$>$ Theme V: Portrayal of Violence or Force Used against Women and Men}

The WHO defines violence against women as "any act of gender-based violence that results in, or is likely to result in, physical, sexual, or mental harm or suffering to women, including threats of such acts, coercion or arbitrary deprivation of liberty, whether occurring in public or in private life" [12]. Violence against women can be further subcategorized into two different forms: intimate partner violence and sexual violence. Intimate partner violence is defined as "the behavior by an intimate partner or ex-partner that causes physical, sexual or psychological harm, including physical aggression, sexual coercion, psychological abuse and controlling behaviors". On the other hand, sexual violence refers to "any sexual act, attempt to obtain a sexual act, or other act directed against a person's sexuality using coercion, by any person regardless of their relationship to the victim, in any setting." Neff explains that possible examples found in lyrics with regards to violence can include slapping, sexual assault, and murder [7]. It is also important to keep in mind that the above-mentioned definition provided by the WHO details violence against women only, not against men. Thus, in order to investigate an expression involving violence against both gender, the same definition of violence against women provided by the WHO has been adopted and modified into an inclusion of men as well.

The lyrics of 20 hip-hop songs were categorized according to the five themes of gender-biased language defined above. To quantify the five themes, the themes were identified and counted based on the word and phrase levels. For example, the lyrics of the song FEFE reads "Got that Super Soaker, hit that, she a Fefe. All I know is that I just can't wife that". In this case the first line, "can't wife" is a 
phrase that exemplifies the Theme II: Portrayal of women in traditional gender roles, by saying that the woman should follow the traditional role of a wife. Thus, it counts as one instance of genderbiased language against women. Also, the word "fefe" (meaning a house party) and the double occurrence of the word "that" in the first and second lyrical lines instance the Theme IV: Objectification of women. The word "fefe" directly refers to the woman being addressed in the song as a "house party" or in other words, objectifying her body. Referring to the woman in the lyrics by "that" instead of "her" equates the woman to an inanimate object. Thus, in the lyrics shown above, it was counted as three instances of gender-biased language against women (e.g., one instance of the Theme II and two occurrences of the Theme IV).

\section{RESUlts AND DisCuSSIONS}

The results of the present study confirmed that gender-biased language exists in contemporary world popular hip-hop music. There was a plethora of gender-biased language against both men and women. A total of 148 gender-biased expressions were found from the selected 20 hip-hop songs. Out of 148 examples, 135 exemplified a bias against women, whereas only 13 examples were against men. This suggests that the vast majority of gender-biased language directs against women. Figure 1 shows the percentage ratio of gender-biased language against women and men.

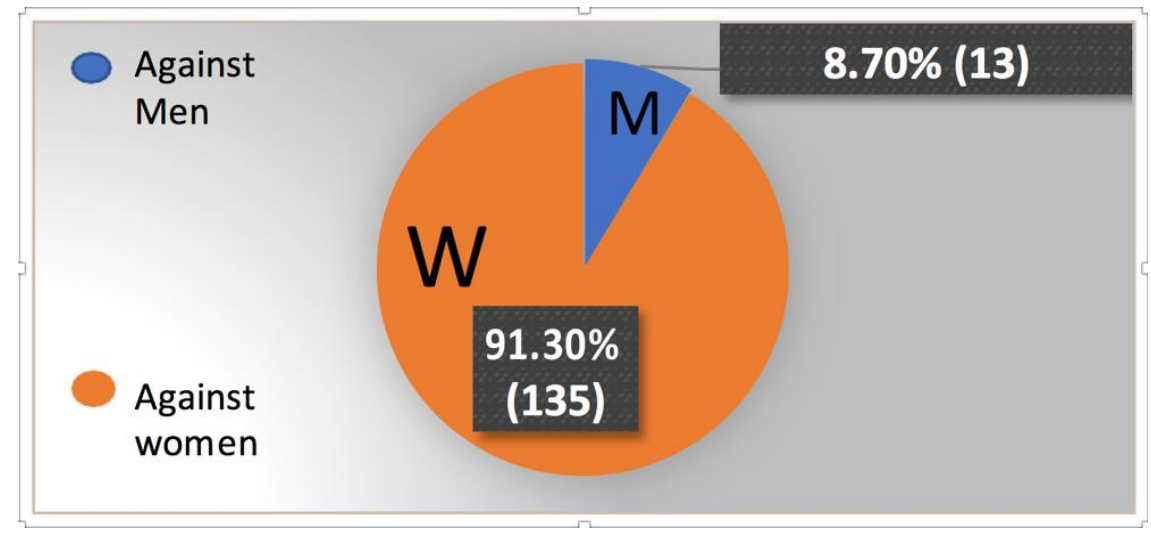

Figure 1. Gender-biased language in hip-hop music

\subsection{Gender-Biased Language against Women}

To identify whether gender-biased language is related to the gender of the singer, the data were further analyzed according to the gender of the singer. In 10 songs by hip-hop male artists, a total of 89 instances of gender-biased language were found, in which 85 examples targeted women and 4 targeted men. On the other hand, in 10 songs by female artists, there was a smaller number of genderbiased expressions. In total, there were 59 instances of gender-biased language, out of which 50 were against women and 9 were against men. Regardless of this difference, there was a similar pattern observed regarding the distribution of gender-biased language in both male and female artists: most of gender-biased discourse was against women regardless of the gender of the artist: $96 \%$ of the examples were against women by male artists and $84.7 \%$ of the examples were also against women by female artists. In other words, despite the low although less frequent than male artists, female artists still portray discourse against their own gender. Figure 2 and 3 illustrate this.

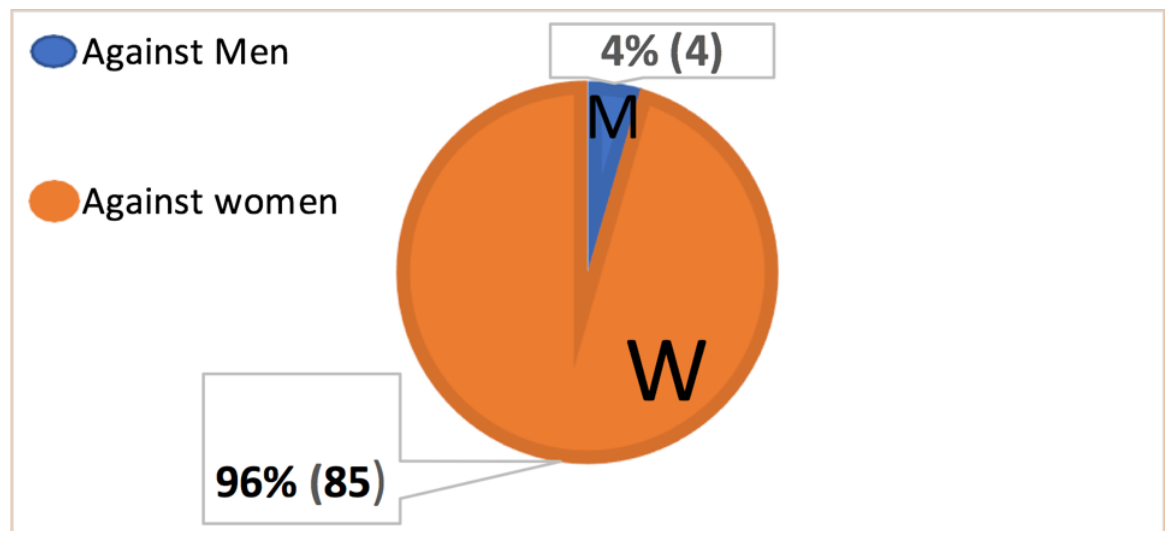

Figure 2. Gender-biased language by male artists 


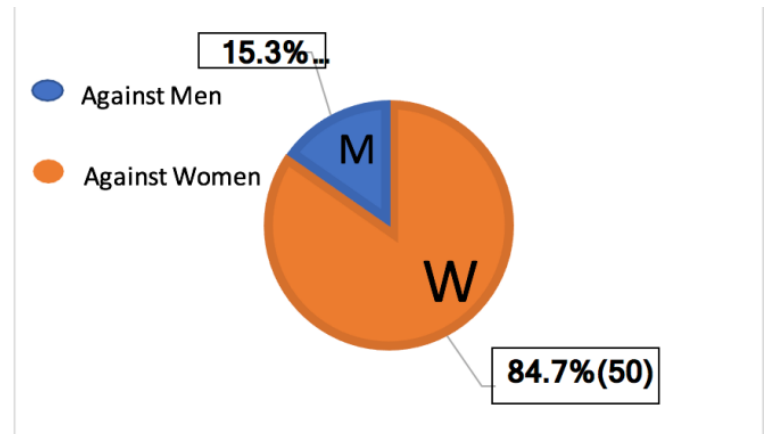

Figure 3. Gender-biased language by female artists

In addition, all the gender-biased expressions used by male and female artists were further analyzed according to the five themes developed in this study. Figure 4 shows different types of gender-biased language against women used by male artists.

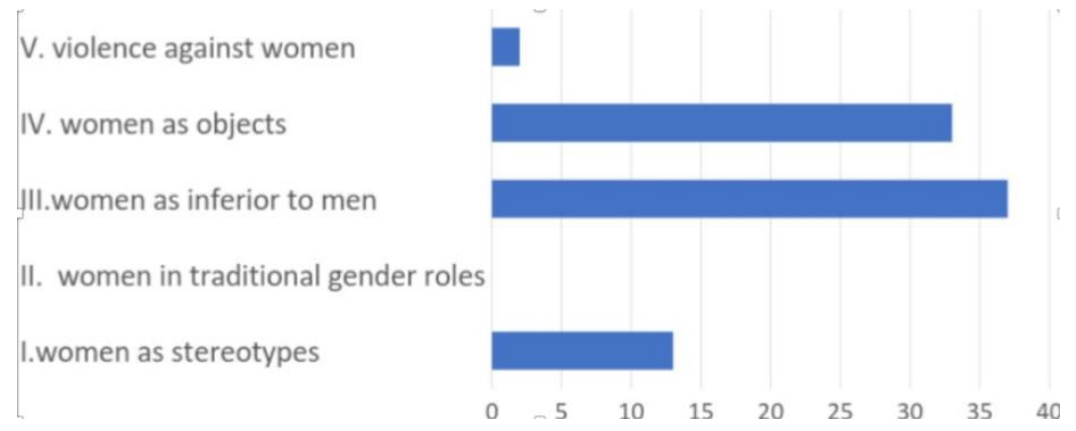

Figure 4. Distribution of gender-biased language against women by male artists

As shown in Figure 4, the Theme III: portrayal of women as inferior to men was the most frequently expressed theme male artists, with 37 instances of gender-biased language against women. Theme IV: Portrayal of women as objects comes at a close end, with a total of 33 instances. Although the number was generally smaller, various phrases expressing violence against women (Theme V) were used by male artists. The two instances were found in the song Life is good, which was ranked \#2 out of 100 songs the Billboard Hot 100 for the week of February 2, 2020. The lyrics goes, "Taliban in this Bitch...Get Osama sprayed in this bitch". Not only does it portray an extreme form of violence against women, but it also expresses a very strong view on a specific religious group, which is a grave topic itself, yet it is beyond the scope of the present study.

What was also very interesting is that there was no instance of the Theme II: Portrayal of women in traditional gender roles. In contrast, there were multiple instances of describing women in nontraditional gender roles by male artists. For example, in the song Bop the artist says, "The women that go to work by day, then, you know dance in the mirror by night", and in Roxanne, the singer describes, "She got the cash app". Both instances suggest that women can earn money on their own, which is contradictory to the stereotypical gender role of a woman.

On the other hand, when analyzing the instances of gender-biased language against women by female artists, a completely different pattern emerged. While the majority of gender-biased language was directed towards women, the distribution of five themes was different between male and female artist groups. Figure 5 shows gender-biased language against women by female artists.

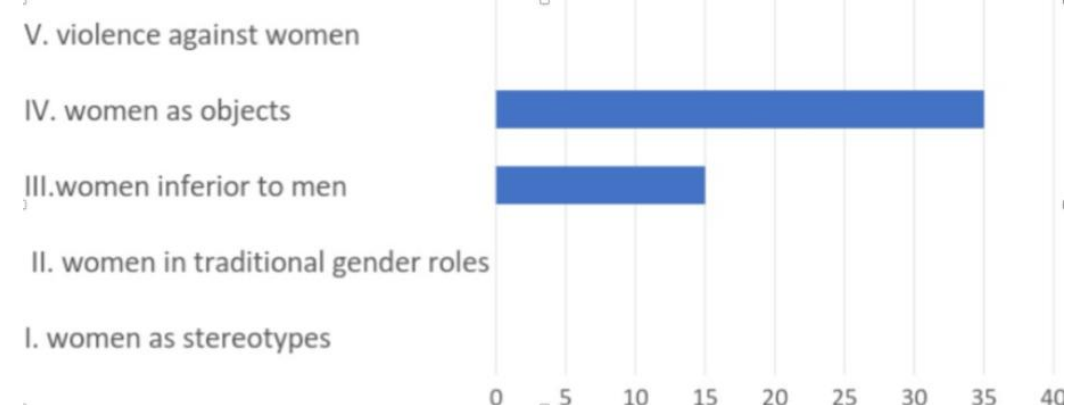

Figure 5. Distribution of gender-biased language against women by female artists 
As shown in Figure 5, only two themes were used by female artists: the Theme IV: Describing women as objects, which occurred 35 times and the Theme III: Portraying women as inferior to men, which occurred 15 times. This suggests that the objectification of women is a very prominent and powerful theme used by female artists. A possible explanation of this is that being a woman is the result of a process of negotiation where objectification of the female body must be present in order for the performer to gain a level of autonomy and to gain exposure.

\subsection{Gender-Biased Language against men}

Gender-biased language against men was also found in hip-hop music, although its occurrence was much lower than that of gender-biased against women (8.7\%, 13 out of 148 instances). Out of 13 cases of gender-biased language against men, 4 were used by male artists and 9 were used by female artists. Similar to the analysis of gender-biased language against women, each and all instances of gender-biased language was analyzed according to the five themes and the gender of the singer, where were summarized in Figures 6 and 7.

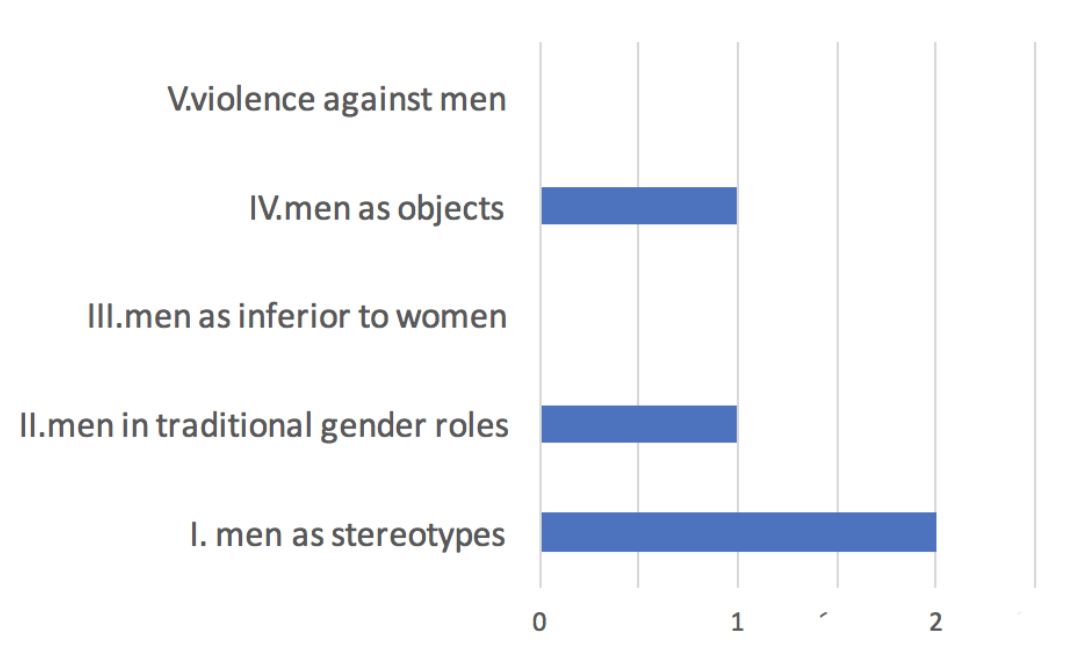

Figure 6. Distribution of gender-biased language against men by male artists

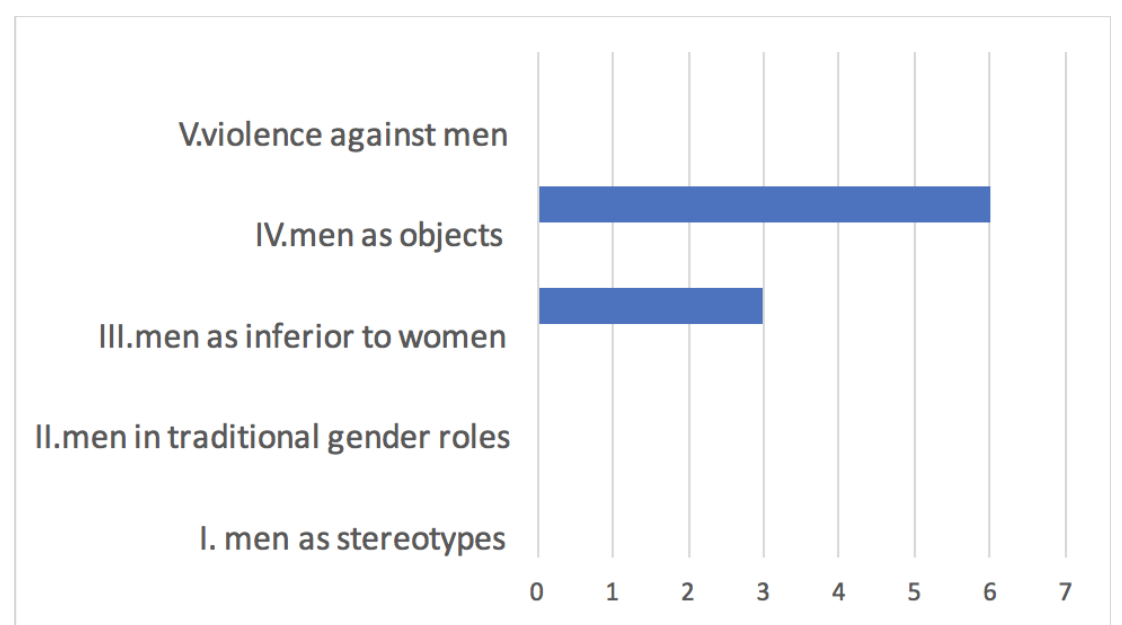

Figure 7. Distribution of gender-biased language against men by female artists

Male artists used three types of gender-biased against their own gender, by portraying men according to the stereotypes, traditional gender roles, and also objectifying themselves. Men were referred to as players, not trustworthy and unfaithful in their relationship. In addition, men were described according to their traditional gender roles, which is exemplified in the lyrics of Bob as in "Nigga gotta get money". This lyrical line emphasizes a very common traditional gender role imposed on men, which is earning money.

On the other hand, female artists predominantly used the Theme III: objectification of men in their using gender-biased language against men, which shows a similar pattern to their use of gender-biased language against women. This suggests that objectification is the most preferred type of gender-biased language used by females against both male and female. 


\section{CONCLUSION}

This study investigated the English lyrics of hip-hop, which is currently mostly preferred music genre in the world. In order to see whether any gender-biased expressions are used and also whether it is related to the gender of the language user/artist, the lyrics of 20 hip-hop songs were analyzed according to different types of gender-biased language against both men and women. The results showed that various types of gender-biased language exist in hip-hop music and both male and female artists predominantly used gender-biased language against women than against men. This suggests that gender-biased language against a specific gender is not related to the gender of the language user. However, a micro-analysis of the data revealed that women and men used language differently. While women mostly objectified both genders in their gender-biased expressions, men used different strategies to describe men and women. Men were described by their traditional roles and stereotypes, whereas women were expressed in a much more offensive way such as depicting violence against women. While music is a great way to learn a foreign language, the findings of the present study suggest that one should be cautious about using it in foreign language education.

\section{REFERENCES}

[1] De Leon, A., "The Complex Intersection of Gender and Hip-Hop," https://www.npr.org/2007/06/06/10783 904/the-complex-intersection-of-gender-and-hip-hop, June 6, 2007.

[2] Murphey, T., The song struck in my head phenomenon: A melodic din in the lad?, System. 18(1), 53-64 (1990).

[3] Prior. J., "What is Gendered Language?", https://www.britishcouncil.org/voices-magazine/what-isgendered-language, 2017.

[4] Chideya, A., "The Complex Intersection of Gender and Hip-Hop," https://www.npr.org/2007/06/06/10783 904/the-complex-intersection-of-gender-and-hip-hop, 2007.

[5] Cobb, M. D. \& Boettcher, W. A. Ambivalent sexism and misogynistic rap music: Does exposure to Eminem increase sexism?, Journal of Applied Social Psychology. 37(2), 3025-3042 (2007).

[6] Emerson, R. A., Where my girls at?, Negotiating black womanhood in music videos, Gender \& Society. 16(1), 115-135 (2002).

[7] Neff, S., Sexism Across Musical Genres: A Comparison. Undergraduate Thesis Western Michigan University. Pp. 38 (2014).

[8] Baxter, J., Positioning gender in discourse: a feminist methodology, Palgrave Macmillan, UK (2003).

[9] Sauntson, H., Approaches to gender and spoken classroom discourse., Palgrave Macmillan, UK. (2011).

[10] United Nations Human Rights, Gender Stereotyping, https://www.ohchr.org/en/issues/women/wrgs/pages/ genderstereotypes.aspx, 2020.

[11] Blackstone, A., Gender Roles and Society, in Julia R. Miller, Richard M. Lerner, and Lawrence B. Schiamberg (eds.), Human Ecology: An Encyclopedia of Children, Families, Communities, and Environments, Santa Barbara, CA: ABC-CLIO, pp. 335-358 (2003).

[12] World Health Organization, Gender. https://www.who.int/health-topics/gender, 2020.

[13] Gendered Innovations, What is Gendered Innovations? http://genderedinnovations.stanford.edu/what-isgendered-innovations.html, 2020

[14] Stanford Encyclopedia of Philosophy, Objectification, https://plato.stanford.edu/entries/feminism-objec tification/, 2019.

Citation: Aya Mohammed Sallam, Ji Young Shim. "Gender-Biased English Language in Hip Hop Music" International Journal on Studies in English Language and Literature (IJSELL), vol 9, no. 2, 2021, pp. 1-7. doi: https://doi.org/10.20431/2347-3134.0902001.

Copyright: () 2021 Authors. This is an open-access article distributed under the terms of the Creative Commons Attribution License, which permits unrestricted use, distribution, and reproduction in any medium, provided the original author and source are credited. 